\title{
Detecting and Managing Small Bowel Crohn's Disease - Capsule Endoscopy Becoming a First Line Diagnostic Method?
}

\author{
Johannes Hausmann and Jörg G Albert* \\ Department of Medicine 1, Johann Wolfgang Goethe University Frankfurt, Frankfurt, Germany
}

\begin{abstract}
Small bowel endoscopy is crucial for diagnosing small bowel Crohn's disease, and capsule endoscopy is complemented by balloon-assisted enteroscopy to take biopsies and by magnetic resonance imaging to visualize enteral and extra-intestinal involvement. Recently, imaging has also become a key instrument to manage Crohn's disease patients. Treatment control is advised for patients who have undergone bowel resections and is increasingly used to testify treatment success in non-operated patients, too. In this review we present the modern imaging methods to diagnose and to manage Crohn's disease with a special focus on the small bowel. Moreover, current knowledge on the impact of diagnostic methods on the patients' outcome is reported.
\end{abstract}

Keywords: Small bowel endoscopy; Capsule endoscopy; Crohn's disease

Abbreviations: AZA: Azathioprine; BAE: Balloon Assisted Enteroscopy; CD: Crohn's Disease; CE: Capsule Endoscopy; CT: Computed Tomography; CT-E: CT-Enteroclysis/Enterography; DBE: Double-Balloon Enteroscopy; IBDU: Unclassified type of Inflammatory Bowel Disease; IFX: Infliximab; MR-E: MR- Enteroclysis/Enterography; MRI: Magnetic Resonance Imaging; MTX: Methotrexate; NSAID: Nonsteroidal Anti-inflammatory Drugs; SBE: Single-Balloon Enteroscopy; UC: Ulcerative Colitis

\section{Introduction}

Crohn's disease (CD) is a chronic inflammatory intestinal disorder that is characterized by episodes when symptoms flare up followed by periods of improvement and clinical remission. The disease is lifelong lasting and frequently manifests in the first decades of life. Clinical symptoms and well-being of the patient is associated to imaging findings of the mucosa and detection of inflammation seems to heavily impact on future prospects of the clinical course of the patient. Ongoing intestinal inflammation- even if subclinical-seems to be responsible for a debilitating course of the disease with evolvement of intestinal strictures and/or occurrence of malnutrition due to reduced nutrient uptake. This may lead to a severely reduced quality of life [1]. The small bowel which is involved in at least $2 / 3$ of the patients has a key role in developing dismal outcome and special attention in surveillance of the small bowel of $\mathrm{CD}$ patients might therefore be of high importance. Several options are available for imaging the small bowel, but diagnostics should ideally be without objection to repeat them, easily and promptly to apply, and without any side effects. Most of these requirements are satisfied by modern diagnostic and imaging techniques. Recently, also the small bowel has become easier to reach by diagnostic endoscopy, i.e. capsule endoscopy (CE), balloon-assisted enteroscopy (BAE), and spiral enteroscopy. High-quality cross sectional imaging completes diagnostic armamentarium, e.g. with using percutaneous ultrasound and magnetic-resonance imaging (MRI) (Figure 1).

We review the modern imaging methods to diagnose and to manage $\mathrm{CD}$ with a special focus on small bowel CD. Moreover, current knowledge on the impact of diagnostic methods on the patients' outcome is reported.

\section{Endoscopic imaging in small bowel Crohn's disease}

Video CE is an easy to administer and non-invasive investigation of the small bowel. After the passage of the intestinal tract the images acquired are reviewed by a specialist. Online visualization of the endoscopic procedure is used to confirm passage progress but not to detect a lesion. To date, four small bowel CE systems are available: PillCam SB2 from Given Imaging, Yoqneam, Israel (http://www. givenimaging.com/); EndoCapsule e.g. from Olympus Europe $\mathrm{GmbH}$, Hamburg, Germany, (http://www.olympuseuropa.com/endoscopy/); OMOM from Chongqing Jinshan Science, Beijing, China, (http:// www.cqjs.net/); Miro-Cam from IntroMedic, Seoul, Korea (http:// www.intromedic.com/). In the USA, only the PillCam SB2 and the Endo Capsule are currently approved by the US Food and Drug

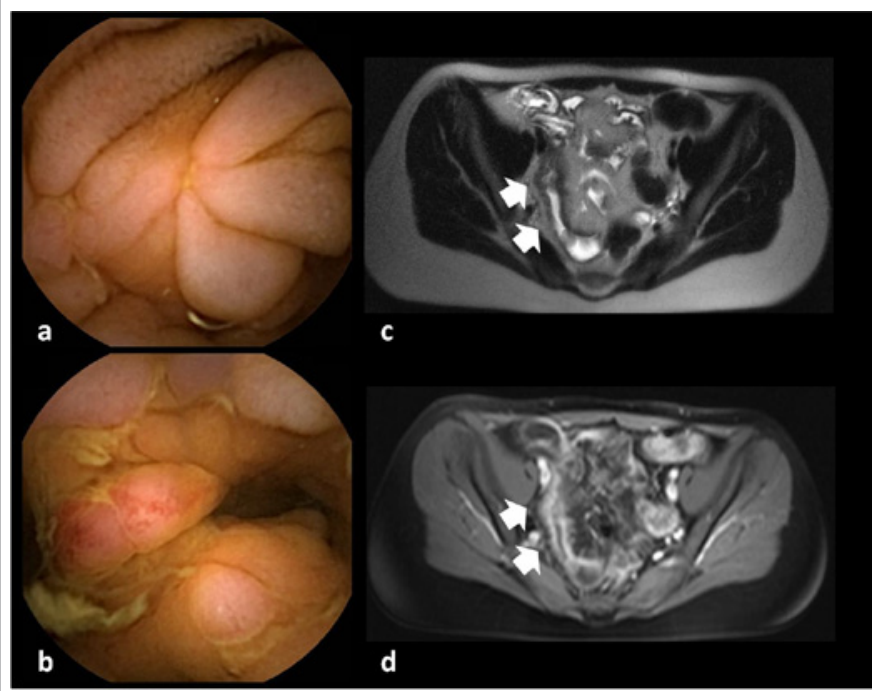

Figure 1: Crohn's disease of the small bowel in capsule endoscopy (CE; a,b) and MRI (c,d). Proximal (a) and distal (b) small bowel Crohn's disease is well detected by CE, and thickening of the small bowel wall is found in T2w (c) and contrast enhancement is seen in GRE sequence (d).

*Corresponding author: J. Albert, MD, Department of Medicine I, Johann Wolfgang Goethe-University Hospital, Theodor-Stern-Kai 7, 60590 Frankfurt, Germany, Fax: 49696301 6247; E-mail: J.Albert@med.uni-frankfurt.de

Received November 06, 2011; Accepted November 13, 2011; Published November 15, 2011

Citation: Hausmann J, Albert JG (2011) Detecting and Managing Small Bowel Crohn's Disease - Capsule Endoscopy Becoming a First Line Diagnostic Method? J Gastrointest Digest Sys S1:002. doi:10.4172/jgds.S1-002

Copyright: (c) 2011 Hausmann J, et al. This is an open-access article distributed under the terms of the Creative Commons Attribution License, which permits unrestricted use, distribution, and reproduction in any medium, provided the original author and source are credited. 
Administration, in Europe all four systems can be purchased in most countries. For most CE studies in CD patients the PillCam SB 2 capsule has been used, which consists of a CMOS-chip with a resolution of 0.1 $\mathrm{mm}$ at a magnification of 1:8. Battery life is $8 \mathrm{~h}$ (SB 2) to about 12-16 hours (SB 2L) (Table 1).

For fear of capsule retention CE is usually not used in patients with known intestinal strictures or potential stenosis but administering patency capsule before performing video $\mathrm{CE}$, capsule retention can reliably be prevented $[2,3]$. The main limitation of the capsule is its inability to take biopsies or to perform interventions, the difficulty with which identified lesions can be accurately localized, and its inability to control its movement.

Balloon-assisted enteroscopy (BAE) involves push-and-pull maneuvers for deep intubation of the small bowel [4] and includes single- and double-balloon enteroscopy techniques (SBE, Olympus, Japan; and DBE, FujiFilm, Japan) [5]. Rate of complete small bowel investigations seems to be more regularly achievable using doubleballoon rather than the single-balloon technique whereas the therapeutic impact was similar with SBE and DBE [6-8]. Complications are reported in less than $5 \%$ of procedures and include pancreatitis $(<1 \%)$, bleeding, and perforation, with the rate of complications increasing in therapeutic interventions [9]. Another enteroscopy technique is the Endo-Ease system (Spirus Medical, Stoughton, MA) that uses a spiral-shaped overtube to advance or withdraw the endoscope with rotatory clockwise and counterclockwise movements of the spiral [10]. Examination time might be reduced, but the insertion depth is minor in comparison with DBE $[11,12]$. With simple pushenteroscopy even less of the small bowel may be intubated [13]. BAE is used to yield biopsies for histopathological examination in patients with newly detected small bowel lesions with suspicion of $\mathrm{CD}$ to exclude neoplastic or infectious disease.

\section{Radiology in imaging small bowel Crohn's disease}

Distension of the intestines by use of luminal contrast is essential to improve characterization of the bowel wall. Thereby, either a sonde is inserted into the proximal small bowel (enteroclysis) or the luminal contrast medium is taken orally (enterography). Conventional fluoroscopy (small bowel follow-through and small bowel enteroclysis) is thereby more and more replaced by cross sectional imaging methods.
For both, Computed tomography (CT) and magnetic resonance imaging (MRI), there have been enterography and enteroclysis techniques developed (CT-enterography/CT-enteroclysis; CT-E or MR-enterography/MR-enteroclysis; MR-E). Thereby, oral contrast application (enterography) provides similar quality of the images but improves patient comfort [14-16]. Inflammatory alterations of the small bowel and extraluminal complications such as abscess or fistula are equally well visualized. Lifetime radiation exposure is a concern, particularly in young patients [16] and doses of more than $100 \mathrm{mSv}$ have been observed in some patients. Lack of radiation and excellent soft tissue contrast argue for use of MRI in CD patients and against fluoroscopy or CT [17-19].

\section{Diagnosing small bowel Crohn's disease: endoscopy vs. cross sectional imaging}

Sequence of investigations and definition of indications for small bowel endoscopy vs. cross sectional imaging is still under debate [20]. Meta-analysis suggests higher sensitivity and optimal negative predictive value of endoscopic methods in comparison to radiology, but extraintestinal lesions are only detected by radiological imaging [21,22] (Table 2).

Consensus conferences cling to a diagnostic sequence in suspected $\mathrm{CD}$ to first perform ileo-colonoscopy for diagnosis of terminal ileitis and colitis, followed by cross sectional imaging to identify proximal $\mathrm{CD}$ or extra-enteric lesions. CE is regarded a final identifier of unexplained symptoms [20,29]. Proximal small bowel CD is best seen with $\mathrm{CE}$, though, and detection of distal small bowel disease is equal sensitive with CTE, MRE, and CE suggests using CE to exclude CD in suspected disease cases: A pooled analysis of the results of $24 \mathrm{CE}$ trails comprising 530 patients found that CE had a low miss rate of $0.5 \%$ for small bowel ulcerations, compared to $79 \%$ of other modalities (SBFT, push-enteroscopy, or ileo-colonoscopy) [31]. Thus, the diagnosis of $\mathrm{CD}$ can possibly most reliably be excluded with a negative $\mathrm{CE}$, even if negative small bowel CE might not completely exclude CD - e.g. of the colon [32]. But, it should be remembered that any diagnostic findings are far from being pathognomonic, and small bowel ulcerations may be compatible with chronic inflammatory, neoplastic, and infectious origin, or might be secondary to NSAID-intake. In a cohort of patients who were suspected to be afflicted with small bowel CD, 37\% of 102 patients were initially diagnosed with small bowel ulcerations by $\mathrm{CE}$, but

\begin{tabular}{|c|c|c|c|c|c|}
\hline Capsule & Company & Size (mm) & Frame rate (Images/s) & Field of view & Acquisition time (hours) \\
\hline PillCam SB 2 & Given imaging, Israel & $11 \times 26$ & 2 & $156^{\circ}$ & 8 (SB 2); ca. 12-16 (SB 2L) \\
\hline EndoCapsule & Olympus, Japan & $11 \times 26$ & 2 & $145^{\circ}$ & $>8$ \\
\hline MiroCam & IntroMedic, Korea & $25 \times 11$ & 3 & - & $>11$ \\
\hline OMOM & Chongqing Jinshan Science, China & $28 \times 13$ & 2 or 1 & $140^{\circ}$ & 8 \\
\hline
\end{tabular}

Table 1: Four capsule endoscopes are available at present.

\begin{tabular}{|c|c|c|c|c|c|c|}
\hline Author & $\mathrm{N}$ & Capsule & opy & Cross section & jing & Statistical significance \\
\hline Eliakim [23] & 2004 & CTE & 35 & $77 \%$ & $20 \%$ & $\mathrm{p}<0.05$ \\
\hline Voderholzer [24] & 2005 & CTE & 41 & $25 / 41(61 \%)$ & $12 / 41(29 \%)$ & $p=0.004$ \\
\hline Hara [25] & 2006 & CT & 17 & $12 / 17(71 \%)$ & 9/17 (53\%) & n.s. \\
\hline Solem [26] & 2008 & CTE & 28 & $83 \%$ & $67 \%$ & n.s. \\
\hline Albert [27] & 2005 & MRI & 52 & $25 / 27(93 \%)$ & $21 / 27(78 \%)$ & n.s. \\
\hline Tillack [51] & 2008 & MRI & 19 & $18 / 19(95 \%)$ & 18/19 (95\%) & n.s. \\
\hline Böcker [30] & 2011 & MRI & 21 & 9/21 (43\%) & $6 / 21(29 \%)$ & Proximal small bowel \\
\hline $\begin{array}{l}\text { Jensen [14] } \\
\text { Casciani [52] }\end{array}$ & $\begin{array}{l}2011 \\
2011\end{array}$ & $\begin{array}{l}\text { MRI and CTE } \\
\text { MRI }\end{array}$ & $\begin{array}{l}93 \\
37\end{array}$ & $\begin{array}{l}100 \% \\
10 / 11(91 \%)\end{array}$ & $\begin{array}{l}81 \% \text { (MRI) } \\
76 \% \text { (CTE) } \\
19 / 19(100 \%)\end{array}$ & $\begin{array}{l}\text { Proximal small bowel } \\
\text { n.s. }\end{array}$ \\
\hline
\end{tabular}

Table 2: Comparison of diagnostic yield or sensitivity in cross sectional imaging techniques and in endoscopy in diagnosing small bowel Crohn's disease; CTE - computed tomography enterography; MRI - magnetic resonance imaging; CE - Capsule endoscopy. 
Citation: Hausmann J, Albert JG (2011) Detecting and Managing Small Bowel Crohn's Disease - Capsule Endoscopy Becoming a First Line Diagnostic Method? J Gastrointest Digest Sys S1:002. doi:10.4172/jgds.S1-002

Page 3 of 5

\begin{tabular}{|c|c|c|c|c|c|c|}
\hline Year & $\mathrm{N}$ & Methods & Treatn & & Diagnostic modality & $\%$ mucosal healing \\
\hline D'Haens [44] & 1997 & 19 & Cohort study & AZA & Ileocolonoscopy & Complete or partial healing: $11 / 15$ \\
\hline D'Haens [45] & 1999 & 30 & $\begin{array}{l}\text { Multicenter, randomized, } \\
\text { double-blind study }\end{array}$ & IFX & Ileocolonoscopy & $\begin{array}{l}\text { IFX: most. } \\
\text { Placebo: none. }\end{array}$ \\
\hline D'Haens [39] & 1999 & 20 & Retrospective study & AZA & Ileocolonoscopy & Complete healing: $12 / 20$ \\
\hline Rutgeerts [46] & 2006 & 99 & $\begin{array}{l}\text { Subgroup of randomized, } \\
\text { double-blind study }\end{array}$ & $\begin{array}{l}\text { IFX, scheduled vs. episodic } \\
\text { treatment }\end{array}$ & Ileocolonoscopy & $\begin{array}{l}\text { Responders (w2), scheduled: } 50 \% \\
\text { Episodic: } 7 \%(p=0.007)\end{array}$ \\
\hline Regueiro [47] & 2009 & 24 & Prospective study & $\begin{array}{l}\text { IFX, prevention of } \\
\text { postoperative recurrence }\end{array}$ & $\begin{array}{l}\text { Ileocolonoscopy, capsule } \\
\text { endoscopy }\end{array}$ & $\begin{array}{l}\text { IFX: } 84.6 \% \\
\text { Placebo: } 9.1 \% \\
(p<0.01)\end{array}$ \\
\hline Schnitzler [43] & 2009 & 214 & Retrospective study & $\begin{array}{l}\text { IFX, scheduled vs. episodic } \\
\text { treatment }\end{array}$ & Ileocolonoscopy & $\begin{array}{l}\text { Scheduled IFX: } 76.9 \% \\
\text { Episodic IFX: } 61.0 \% \\
(p=0.02\end{array}$ \\
\hline Colombel [48] & 2010 & 508 & $\begin{array}{l}\text { Randomized, double-blind } \\
\text { study }\end{array}$ & IFX, AZA, IFX + AZA & Ileocolonoscopy & $\begin{array}{l}\text { IFX + AZA: } 43.9 \% \\
\text { IFX: } 30.1 \%(p=0.06) \\
\text { AZA: } 16.5 \%(p<0.05\end{array}$ \\
\hline Baert [41] & 2010 & 49 & Cohort of randomized study & $A Z A+I F X$ vs. placebo & lleocolonoscopy & $\begin{array}{l}\text { Maintenance of remission with no } \\
\text { therapy: } 15 / 17\end{array}$ \\
\hline Laharie [49] & 2011 & 51 & Retrospective study & MTX, AZA, or IFX & Ileocolonoscopy & $\begin{array}{l}\text { MTX: } 11 \% \\
\text { AZA: } 50 \%(p=0.011 \text { vs. MTX }) \\
\text { IFX: } 60 \%(p=0.008)\end{array}$ \\
\hline
\end{tabular}

Table 3: Mucosal healing in terms of immunosuppressive therapy as determined by endoscopic findings. IFX- infliximab, AZA - azathioprine, MTX - methotrexate, CD Crohn's disease, UC - ulcerative colitis.

only $13 \%$ had the diagnosis of CD maintained at one year of follow-up [33]. Even if some features of small bowel lesions might rather suggest $\mathrm{CD}$ (irregular and longitudinal ulcerations, multiple locations, cobble stone aspect of the small bowel) than NSAID use (circular ulcerations, webs) or neoplasia (circumscribed lesion), these identifier must be interpreted very cautious before labeling a patient to be affected by CD. In established $\mathrm{CD}$, immediate access to cross sectional imaging (e.g. MRI) is important in many clinical scenarios such as the septic patient, or in ileus, and severe intestinal inflammation, suppurative disease, and conglomerate tumor or fistulae can be detected. Endoscopy is necessary to discriminate inflammatory from chronic, non-inflammatory lesions or strictures. In the unclassified type of inflammatory bowel disease (IBDU) it may be reasonable to screen for small bowel involvement to confirm the diagnosis of $\mathrm{CD}$ in some patients. In one study, the diagnosis of IBDU had been revised and changed to CD in $15 \%$ of 120 patients [34,32] but minor findings should not mislead to revise the diagnosis [35]. Postoperatively endoscopic surveillance is recommended [30] and inflammatory lesions are best discriminated from non-inflammatory bowel alterations by use of endoscopy. Hereby, CE might replace ileo-colonoscopy to detect recurrence, as accuracy of $\mathrm{CE}$ is similar to conventional colonoscopy in the anastomotic region, but proximal disease is exclusively visualized by $\mathrm{CE}[36,37]$.

\section{Outcome in terms of mucosal healing}

Endoscopy has been used to detect CD activity in the postoperative situation, i.e. in a high-risk group of patients who were prone to undergo a complicated disease course with high probability to be in need of further surgery. In this patient group, the future course of the disease was best predicted by the severity of the early postoperative lesions, as observed at ileo-colonoscopy [38]. Since then, endoscopic treatment control in the postoperative patient group is well established with endoscopy being the golden standard of surveillance [38]. Endoscopy has increasingly been used to document on mucosal healing in CD patients and in ulcerative colitis, and mucosal healing has more and more been established as an important sign of treatment efficacy and a reliable prognostic marker, table 3. Mucosal healing has been described in $\mathrm{CD}$ patients who were on Azathioprine and who experienced complete healing of their colitis that was confirmed by disappearance of the inflammatory infiltrate in histopathologic examination [39]. Mucosal healing as documented by endoscopy after
1 year of treatment has been found to predict reduced subsequent disease activity over the following five years and decreased need for active treatment [40]. Recently, complete mucosal healing was found to be associated with a sustained, steroid-free remission in early-stage Crohn's disease [41]. Thereby, endoscopic monitoring the treatment has been shown ideal to identify those patients that are at high-risk of a dismal outcome: At 3 months from the start of IFX therapy, endoscopic investigations correctly predicted responders of maintenance therapy in active luminal CD [42]. Moreover, mucosal healing was associated with an improved long-term outcome with lesser need for major abdominal surgeries [43] (Table 3).

Today, endoscopic surveillance is used to assess disease activity and mucosal healing in patients with persistent symptoms despite therapy and when treatment discontinuation is considered. Regular, scheduled screening endoscopies are not established. Ileocolonoscopy is the standard procedure in use, even if CE or colon CE could be used to visualize both, the small and the large intestines. Thus, a recent study demonstrated that the findings of CE had a serious impact on clinical practice with a change of management in $50 \%$ of the patients with established or suspected CD [50].

\section{Conclusion}

Small bowel endoscopy is crucial for diagnosing small bowel CD, and $\mathrm{CE}$ is complemented by BAE to take biopsies and by MRI to visualize enteral and extra-intestinal involvement. Recently, imaging has also become a key instrument to manage CD patients. Treatment control is advised for patients who have undergone bowel resections and is increasingly used to testify treatment success in non-operated patients, too. Recent studies have illustrated the higher sensitivity of $\mathrm{CE}$ to detect small bowel lesions in comparison to radiology and clinical impact of the findings has been demonstrated. Further studies are needed to evaluate the exact clinical role of small bowel $\mathrm{CE}$, colonic $\mathrm{CE}$, and maybe pan-intestinal $\mathrm{CE}$ in the management of $\mathrm{CD}$.

\section{References}

1. D'Haens GR, Panaccione R, Higgins PD, Vermeire S, Gassull M, et al. (2011) The London Position Statement of the World Congress of Gastroenterology on Biological Therapy for IBD with the European Crohn's and Colitis Organization: when to start, when to stop, which drug to choose, and how to predict response? Am J Gastroenterol 106: 199-212. 
2. Signorelli C, Rondonotti E, Villa F, Abbiati C, Beccari G, et al. (2006) Use of the Given Patency System for the screening of patients at high risk for capsule retention. Dig Liver Dis 38: 326-330.

3. Spada C, Riccioni ME, Costamagna G (2007) Patients with known small bowe stricture or with symptoms of small bowel obstruction secondary to Crohn's disease should not perform video capsule endoscopy without being previously tested for small bowel patency. Am J Gastroenterol 102: 1542-1543.

4. May A, Nachbar L, Schneider M, Neumann M, Ell C (2005) Push-and-pul enteroscopy using the double-balloon technique: method of assessing depth of insertion and training of the enteroscopy technique using the Erlangen EndoTrainer. Endoscopy 37: 66-70.

5. Gerson LB, Flodin JT, Miyabayashi K (2008) Balloon-assisted enteroscopy: technology and troubleshooting. Gastrointest Endosc 68: 1158-1167.

6. May A, Färber M, Aschmoneit I, Pohl J, Manner H, et al. (2010) Prospective multicenter trial comparing push-and-pull enteroscopy with the single- and double-balloon techniques in patients with small-bowel disorders. Am J Gastroenterol 105: 575-581.

7. Domagk D, Mensink P, Aktas H, Lenz P, Meister T, et al. (2011) Singlevs. double-balloon enteroscopy in small-bowel diagnostics: a randomized multicenter trial. Endoscopy 43: 472-476.

8. Takano N, Yamada A, Watabe H, Togo G, Yamaji Y, et al. (2011) Singleballoon versus double-balloon endoscopy for achieving total enteroscopy: a randomized, controlled trial. Gastrointest Endosc 73: 734-739.

9. Möschler O, May A, Müller MK, Ell C, German DBE Study Group (2011) Complications in and performance of double-balloon enteroscopy (DBE): results from a large prospective DBE database in Germany. Endoscopy 43: 484-489.

10. Judah JR, Draganov PV, Lam Y, Hou W, Buscaglia JM (2010) Spira enteroscopy is safe and effective for an elderly United States population of patients with numerous comorbidities. Clin Gastroenterol Hepatol 8: 572-576.

11. May A, Manner H, Aschmoneit I, Ell C (2011) Prospective, cross-over, singlecenter trial comparing ororal double-balloon enteroscopy and oral spiral enteroscopy in patients with suspected small-bowel vascular malformations. Endoscopy 43: 477-483.

12. Frieling T, Heise J, Sassenrath W, Hulsdonk A, Kreysel C (2010) Prospective comparison between double-balloon enteroscopy and spiral enteroscopy. Endoscopy 42: 885-888.

13. Perez-Cuadrado E, Macenlle R, Iglesias J, Fabra R, Lamas D (1997) Usefulness of oral video push enteroscopy in Crohn's disease. Endoscopy 29: 745-747.

14. Jensen MD, Nathan T, Rafaelsen SR, Kjeldsen J (2011) Diagnostic accuracy of capsule endoscopy for small bowel Crohn's disease is superior to that of MR enterography or CT enterography. Clin Gastroenterol Hepatol 9: 124-129.

15. Masselli G, Casciani E, Polettini E, Gualdi G (2008) Comparison of MR enteroclysis with MR enterography and conventional enteroclysis in patients with Crohn's disease. Eur Radiol 18: 438-447.

16. Schreyer AG, Geissler A, Albrich H, Schölmerich J, Feuerbach S, et al. (2004) Abdominal MRI after enteroclysis or with oral contrast in patients with suspected or proven Crohn's disease. Clin Gastroenterol Hepatol 2: 491-497.

17. Brenner DJ, Hall EJ (2007) Computed tomography--an increasing source of radiation exposure. N Engl J Med 357: 2277-2284.

18. Gaca AM, Jaffe TA, Delaney S, Yoshizumi T, Toncheva G, et al. (2008) Radiation doses from small-bowel follow-through and abdomen/pelvis MDCT in pediatric Crohn disease. Pediatr Radiol 38: 285-291.

19. Desmond AN, O'Regan K, Curran C, McWilliams S, Fitzgerald T, et al. (2008) Crohn's disease: factors associated with exposure to high levels of diagnostic radiation. Gut 57: 1524-1529.

20. Bourreille A, Ignjatovic A, Aabakken L, Loftus EV Jr, Eliakim R, et al. (2009) Role of small-bowel endoscopy in the management of patients with inflammatory bowel disease: an international OMED-ECCO consensus. Endoscopy 41: 618637.

21. Triester SL, Leighton JA, Leontiadis GI, Gurudu SR, Fleischer DE, et al. (2006) A meta-analysis of the yield of capsule endoscopy compared to other diagnostic modalities in patients with non-stricturing small bowel Crohn's disease. Am J Gastroenterol 101: 954-964.

22. Dionisio PM, Gurudu SR, Leighton JA, Leontiadis GI, Fleischer DE, et al.
(2010) Capsule endoscopy has a significantly higher diagnostic yield in patients with suspected and established small-bowel Crohn's disease: a meta-analysis. Am J Gastroenterol 105: 1240-1248.

23. Eliakim R, Suissa A, Yassin K, Katz D, Fischer D (2004) Wireless capsule video endoscopy compared to barium follow-through and computerised tomography in patients with suspected Crohn's disease--final report. Dig Liver Dis 36: 519 522

24. Voderholzer WA, Beinhoelzl J, Rogalla P, Murrer S, Schachschal G, et al (2005) Small bowel involvement in Crohn's disease: a prospective comparison of wireless capsule endoscopy and computed tomography enteroclysis. Gut 54: 369-373

25. Hara AK, Leighton JA, Heigh RI, Sharma VK, Silva AC, et al. (2006) Crohn disease of the small bowel: preliminary comparison among CT enterography, capsule endoscopy, small-bowel follow-through, and ileoscopy. Radiology 238 : 128-134.

26. Solem CA, Loftus EV Jr, Fletcher JG, Baron TH, Gostout CJ, et al. (2008) Smallbowel imaging in Crohn's disease: a prospective, blinded, 4-way comparison trial. Gastrointest Endosc 68: 255-266.

27. Albert JG, Martiny F, Krummenerl A, Stock K, Lesske J, et al. (2005) Diagnosis of small bowel Crohn's disease: a prospective comparison of capsule endoscopy with magnetic resonance imaging and fluoroscopic enteroclysis. Gut 54: 1721-1727.

28. Gölder SK, Schreyer AG, Endlicher E, Feuerbach S, Schölmerich J, et al (2006) Comparison of capsule endoscopy and magnetic resonance (MR) enteroclysis in suspected small bowel disease. Int J Colorectal Dis 21: 97-104.

29. Verdonk RC, Buis Cl, Porte RJ, van der Jagt EJ, Limburg AJ, et al. (2006) Anastomotic biliary strictures after liver transplantation: causes and consequences. Liver Transpl 12: 726-735.

30. Böcker U, Dinter D, Litterer C, Hummel F, Knebel P, et al. (2010) Comparison of magnetic resonance imaging and video capsule enteroscopy in diagnosing small-bowel pathology: localization-dependent diagnostic yield. Scand J Gastroenterol 45: 490-500

31. Lewis BS, Eisen GM, Friedman S (2005) A pooled analysis to evaluate results of capsule endoscopy trials. Endoscopy 37: 960-965.

32. Maunoury V, Savoye G, Bourreille A, Bouhnik Y, Jarry M, et al. (2007) Value of wireless capsule endoscopy in patients with indeterminate colitis (inflammatory bowel disease type unclassified). Inflamm Bowel Dis 13: 152-155.

33. Tukey M, Pleskow D, Legnani P, Cheifetz AS, Moss AC (2009) The utility of capsule endoscopy in patients with suspected Crohn's disease. Am J Gastroenterol 104: 2734-2739.

34. Mehdizadeh S, Chen G, Enayati PJ, Cheng DW, Han NJ, et al. (2008) Diagnostic yield of capsule endoscopy in ulcerative colitis and inflammatory bowel disease of unclassified type (IBDU). Endoscopy 40: 30-35.

35. Bousvaros A, Antonioli DA, Colletti RB, Dubinsky MC, Glickman JN, et al (2007) Differentiating ulcerative colitis from Crohn disease in children and young adults: report of a working group of the North American Society for Pediatric Gastroenterology, Hepatology, and Nutrition and the Crohn's and Colitis Foundation of America. J Pediatr Gastroenterol Nutr 44: 653-674

36. Bourreille A, Jarry M, D'Halluin PN, Ben-Soussan E, Maunoury V, et al. (2006) Wireless capsule endoscopy versus ileocolonoscopy for the diagnosis of postoperative recurrence of Crohn's disease: a prospective study. Gut 55: 978 983.

37. Pons Beltrán V, Nos P, Bastida G, Beltrán B, Argüello L, et al. (2007) Evaluation of postsurgical recurrence in Crohn's disease: a new indication for capsule endoscopy? Gastrointest Endosc 66: 533-540.

38. Rutgeerts P, Geboes K, Vantrappen G, Beyls J, Kerremans R, et al. (1990) Predictability of the postoperative course of Crohn's disease. Gastroenterology 99: 956-963.

39. D'Haens G, Geboes K, Rutgeerts P (1999) Endoscopic and histologic healing of Crohn's (ileo-) colitis with azathioprine. Gastrointest Endosc 50: 667-671.

40. Frøslie KF, Jahnsen J, Moum BA, Vatn MH, IBSEN Group (2007) Mucosa healing in inflammatory bowel disease: results from a Norwegian populationbased cohort. Gastroenterology 133: 412-422.

41. Baert F, Moortgat L, Van Assche G, Caenepeel P, Vergauwe P, et al. (2010) Mucosal healing predicts sustained clinical remission in patients with earlystage Crohn's disease. Gastroenterology 138: 463-468. 
Citation: Hausmann J, Albert JG (2011) Detecting and Managing Small Bowel Crohn's Disease - Capsule Endoscopy Becoming a First Line Diagnostic Method? J Gastrointest Digest Sys S1:002. doi:10.4172/jgds.S1-002

Page 5 of 5

42. af Björkesten CG, Nieminen U, Turunen U, Arkkila PE, Sipponen T, et al. (2011) Endoscopic monitoring of infliximab therapy in Crohn's disease. Inflamm Bowel Dis 17: 947-953

43. Schnitzler F, Fidder H, Ferrante M, Noman M, Arijs I, et al. (2009) Mucosal healing predicts long-term outcome of maintenance therapy with infliximab in Crohn's disease. Inflamm Bowel Dis 15: 1295-1301.

44. D'Haens G, Geboes K, Ponette E, Penninckx F, Rutgeerts P (1997) Healing of severe recurrent ileitis with azathioprine therapy in patients with Crohn's disease. Gastroenterology 112: 1475-1481.

45. D'haens G, Van Deventer S, Van Hogezand R, Chalmers D, Kothe C, et al. (1999) Endoscopic and histological healing with infliximab anti-tumor necrosis factor antibodies in Crohn's disease: A European multicenter trial. Gastroenterology 116: 1029-1034.

46. Rutgeerts P, Diamond RH, Bala M, Olson A, Lichtenstein GR, et al. (2006) Scheduled maintenance treatment with infliximab is superior to episodic treatment for the healing of mucosal ulceration associated with Crohn's disease. Gastrointest Endosc 63: 433-442.

47. Regueiro M, Schraut W, Baidoo L, Kip KE, Sepulveda AR, et al. (2009) Infliximab prevents Crohn's disease recurrence after ileal resection. Gastroenterology 136: $441-450$.

48. Colombel JF, Sandborn WJ, Reinisch W, Mantzaris GJ, Kornbluth A, et al (2010) Infliximab, azathioprine, or combination therapy for Crohn's disease. N Engl J Med 362: 1383-1395.

49. Laharie D, Reffet A, Belleannee G, Chabrun E, Subtil C, et al. (2011) Mucosa healing with methotrexate in Crohn's disease: a prospective comparative study with azathioprine and infliximab. Aliment Pharmacol Ther 33: 714-721.

50. van Tuyl S, van Noorden JT, Stolk MF, Kuipers EJ (2007) Clinical consequences of videocapsule endoscopy in GI bleeding and Crohn's disease. Gastrointest Endosc 66: 1164-1170.

51. Tillack C, Seiderer J, Brand S, Goke B, Reiser MF, et al. (2008) Correlation of magnetic resonance enteroclysis (MRE) and wireless capsule endoscopy (CE) in the diagnosis of small bowel lesions in Crohn's disease. Inflamm Bowel Dis 14: $1219-1228$.

52. Casciani E, Masselli G, Di Nardo G, Polettini E, Bertini L, et al. (2011) MR enterography versus capsule endoscopy in paediatric patients with suspected Crohn's disease. Eur Radiol. 2011; 21:823-31.
This article was originally published in a special issue, Video Capsule Endoscopy handled by Editor(s). Dr. Sherman M. Chamberlain, Georgia Health Services University, USA
Submit your next manuscript and get advantages of OMICS Group submissions

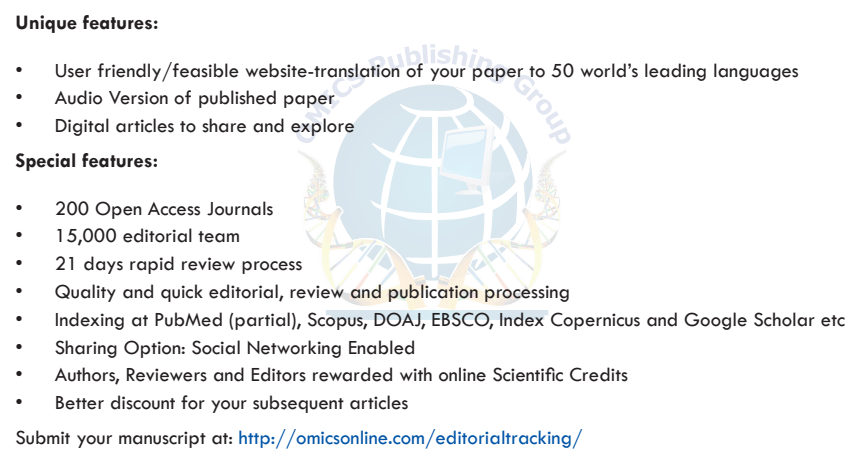

